\title{
Characterization of human malignant mesothelioma cell lines orthotopically implanted in the pleural cavity of immunodeficient mice for their ability to grow and form metastasis Daniele Martarelli*1, Alfonso Catalano², Antonio Procopio ${ }^{2}$, Sara Orecchia ${ }^{3}$, Roberta Libener ${ }^{3}$ and Giorgio Santoni ${ }^{1}$
}

Address: ${ }^{1}$ Department of Experimental Medicine and Public Health, University of Camerino, 62032 Camerino, Italy, ${ }^{2}$ Department of Molecular Pathology and Innovative Therapies, Polytechnic University of Marche, 60100, Ancona, Italy and Center of Cytology, Italian National Research Centers on Aging (INRCA - IRCCS), Ancona, Italy and ${ }^{3}$ Pathology Unit, Dept. Of Oncology, A.S.O. Alessandria, Italy

Email: Daniele Martarelli* - daniele.martarelli@unicam.it; Alfonso Catalano - catgfp@yahoo.it; Antonio Procopio - procopio@mta01.unian.it; Sara Orecchia - saraorecchia@yahoo.it; Roberta Libener - rlibener@ospedale.al.it; Giorgio Santoni - giorgio.santoni@unicam.it

* Corresponding author

Published: 17 May 2006

BMC Cancer 2006, 6:130 doi:10.1186/147|-2407-6-130
Received: 28 July 2005

Accepted: 17 May 2006

This article is available from: http://www.biomedcentral.com//47/-2407/6//30

() 2006 Martarelli et al; licensee BioMed Central Ltd.

This is an Open Access article distributed under the terms of the Creative Commons Attribution License (http://creativecommons.org/licenses/by/2.0), which permits unrestricted use, distribution, and reproduction in any medium, provided the original work is properly cited.

\begin{abstract}
Background: Malignant pleural mesothelioma (MPM) is a tumor known to be resistant to conventional therapies. Thus, an in vivo model can represent an important tool for assessing the efficacy of novel approaches in the treatment of MPM.

Presently, human MPM cells have been grown orthotopically in mice upon transplantation of tumor masses or tumor cell suspensions following surgery. In these models however, surgery can interfere with the tumor growth and the early stages of tumor development cannot be easily explored. Finally, results may not be so accurate due to implantation of potentially different tumor samples in different experimental groups.
\end{abstract}

Our work aimed at establishing a nude mouse model xenotransplanted with human MPM cell lines in which tumor progression exhibits some features of the human disease.

Methods: Three distinct human MPM cell lines previously established from MPM patients displaying two different phenotypes, biphasic (MM-BI and IST-Mes3) and epithelioid (IST-Mes2), were directly injected into the pleural cavity of nude mice. At different times, mice were sacrificed for autopsy, tumor nodules were counted and then removed for histology. Presence of metastases in visceral organs was also monitored.

Results: IST-Mes2 cells were unable to grow in nude mice. MM-BI and IST-Mes3 cells were capable of growing in nude mice and formed tumor nodules in the pleura. Post-mortem examination showed that MPM cells progressively colonized the parietal and visceral pleura, the diaphragm, the mediastinum and, lastly the lung parenchyma. No pneumo-thorax was evidenced in the mice. Pleural effusions as well as lymph node metastases were observed only at later times.

Conclusion: This model mimics the progression of human malignant mesothelioma and it is easy to perform and reproducible; therefore it can be useful to study human MPM biology and evaluate the efficacy of novel therapies. 


\section{Background}

Malignant pleural mesothelioma is a tumor of the pleura mainly caused by exposure to asbestos fibers. MPM diagnosis regards about 2500 persons every year in the United States [1] and the prognosis is poor despite the therapies currently used, including surgery, radiotherapy and chemotherapy.

Because of the inefficacy of the conventional treatments, novel therapeutic strategies are under investigation, with particular attention devoted to agents capable of inhibiting the angiogenesis or inducing tumor cell apoptosis [27].

Tumor angiogenesis, apoptosis and metastasis, strictly depend on the site of tumor development; therefore a human-like animal model is an important tool for studying new approaches for MPM treatment.

A number of evidences indicate that orthotopic models of tumor growth are more valuable as compared to those in which the tumor mass grows subcutaneously [8].

In regard to MPM, subcutaneous implantation of human cancer cells in immunodeficient mice results in tumor growth at the injection site and no metastatic dissemination, whereas human MPM growth in humans is associated with regional tumor spreading and lung invasion [9].

Presently, human MPM cells have been grow orthotopically in mice upon transplantation of tumor masses or tumor cell suspensions following surgery [10]. In these models however, surgery can interfere with the tumor growth [8] and the early stages of tumor development cannot be easily explored. Finally, results may be not so accurate due to implantation of potentially different tumor samples in different experimental groups [9]. Overall, the aim of this work was to establish a new orthotopic tumor model by injecting human MPM cells directly into the pleural cavity of nude mice. This model does not need surgical operations, can be easily performed and more importantly can mimic tumor development in humans. Thus it can represent an useful tool for studying human MPM biology and assessing the efficacy of novel therapies.

\section{Methods \\ Cell lines}

Human malignant pleura mesothelial cell lines were established as previously described $[11,12]$. Three distinct cell lines with two different phenotypes, biphasic (MM-B1 and IST-Mes3) and epithelioid (IST-Mes2) were used between the eighth and twelfth passage in culture. Cells were maintained in RPMI- 1640 medium and $10 \%$ fetal bovine serum, $1 \% \mathrm{~L}$-glutamine and $1 \%$ penicillin-strepto- mycin, (Euroclone, Devon, UK) at $37^{\circ} \mathrm{C}$ in a humidified incubator in an atmosphere of 5\% $\mathrm{CO} 2$ in air.

\section{Animals}

Athymic male nude mice nu/nu (Harlan, Italy), 6 weekold were used. Mice were kept in laminar-flow cages in standardized environmental conditions. Sterilized food (Harlan, Italy) and water were supplied ad libitum.

\section{Subcutaneous implantation of MPM cells in nude mice}

Cells were harvested at near confluence with trypsin/ EDTA solution. Only cell suspensions with a viability of $>90 \%$ as assessed by trypan blue exclusion assay, were used. Two $\times 10^{6} \mathrm{MPM}$ cells in $100 \mu \mathrm{l}$ of $\mathrm{Ca}++$ and $\mathrm{Mg}++$ free Hank's balanced salt solution (HBSS) were injected subcutaneously on the left lateral chest wall near to the axilla. Tumor growth was monitored twice a week using a caliper. Tumor volume was calculated using the formula: $\mathrm{V}(\mathrm{mm} 3)=(\mathrm{D} \times \mathrm{d} 2) / 2$, where $\mathrm{d}(\mathrm{mm})$ and $\mathrm{D}(\mathrm{mm})$ are the smallest and largest perpendicular tumor diameter, respectively.

\section{Orthotopic implantation of MPM cells in nude mice}

Mice were anaesthetized with Tiletamine chlorohydrate and Zolazepam chlorohydrate and placed in position of right lateral decubitus. A 27 gauge needle of a $1000 \mu \mathrm{l}$ syringe was advanced approximately through the fourth intercostal space for about $5 \mathrm{~mm}$, into the left pleural cavity, and two $\times 10^{6}$ tumor cells suspended in $100 \mu \mathrm{l}$ of HBSS were injected. The site of injection in the chest and the precise depth of the needle tip required to reach the pleural space were previously determined by injecting cresyl violet. A primary tumor cell line IST-Mes3/2P (ISTMes3/2nd Passage) was established from a IST-Mes3 tumor grown orthotopically. Tumors were grounded into small pieces in RPMI-1640 and digested with trypsin/ EDTA solution. The cell suspension was then plated in a $75 \mathrm{ml}$ culture flask and the following day, non adherent cells were removed. Cells were maintained in culture, and $2 \times 10^{6}$ cells were injected into the pleural cavity of nude mice when devoid of fibroblasts or endothelial cells.

\section{Therapeutic procedures}

Four groups of animals were used. The first group of animals were used to analyze the tumorigenicity of MPM cell lines after orthotopic or subcutaneous implantation in nude mice. Animals were then injected with MPM cells as reported in Table 1.

The second, third and fourth groups were used to analyze the growth rate of IST-Mes3, IST-Mes3/2P and MM-B1 cells respectively after orthotopic implantation in mice. 
Table I: Tumorigenicity of MPM cell lines after orthotopic and subcutaneous implantation in nude mice.

\begin{tabular}{llllll}
\hline Cell line & Histology & Tumorigenicity & Implantation method & Survival(days) (mean \pm SD) & Survival (days) (Min/Max) \\
\hline IST-Mes2 & Epithelioid & $0 / 15$ & Orthotopic & - & - \\
& Epithelioid & $0 / 15$ & Subcutaneous & - & - \\
IST-Mes3 & Biphasic & $15 / 15$ & Orthotopic & $81,5 \pm 21,7$ & $60 / 122$ \\
& Biphasic & $15 / 15$ & Subcutaneous & Sacrificed after 90 days & - \\
IST-Mes3/2P & Biphasic & $15 / 15$ & Orthotopic & $69,6 \pm 14,5$ & $54 / 89$ \\
MM-BI & Biphasic & $15 / 15$ & Orthotopic & $72,5 \pm 6,4$ & $68 / 77$ \\
& Biphasic & $0 / 15$ & Subcutaneous & - & - \\
\hline
\end{tabular}

$2 \times 10^{6}$ MPM cells were injected into the pleural cavity of nude mice. The experiment ended when mice were moribund.

\section{Autopsy and histology}

Mice were sacrificed at different times following tumor cell injection as specified.

Tumor nodules were counted, measured with the caliper, removed, immediately snap frozen in liquid nitrogen and stored at $-80^{\circ} \mathrm{C}$. The presence of metastasis in the visceral organs was macroscopically checked.

\section{Immunohistochemistry}

Microvessel density (MVD) was determined by using the endothelial cell marker CD31. Tumors were placed in OTC compound and snap frozen in liquid nitrogen and stored at $-80^{\circ} \mathrm{C}$. Frozen section $(10-20 \mu \mathrm{m})$ were fixed with cold acetone ( $5 \mathrm{~min})$, acetone/chlorophorm 1/1 (5 $\mathrm{min}$ ) and cold acetone ( $5 \mathrm{~min})$. Samples were then rinsed with PBS/Triton 1\%, and treated with 3\% hydrogen peroxide in methanol ( $\mathrm{vol} / \mathrm{vol})$. Slides were incubated in a blocking solution and then overnight at $4{ }^{\circ} \mathrm{C}$ in a humidified chamber with a rat anti-mouse CD31 monoclonal antibody (BD Biosciences Pharmingen, NJ, USA). Thereafter, slides were rinsed with PBS and incubated, first with the blocking solution for $20 \mathrm{~min}$ and then with a biotinconjugated goat anti-rat antibody (Santa Cruz Biotechnology, CA, USA) for $1 \mathrm{~h}$. Slides were then rinsed with PBS and incubated for $30 \mathrm{~min}$ with the Vector Vectastain $\mathrm{ABC}$ Kit (Vinci-Biochem, Vinci, FI). After 3 washes with PBS, positive reactions were visualized by incubating the slides for 5 min with stable DAB (Sigma, Italy). Slides were dried and mounted with Universal Mount.
For mesothelioma markers, 3-4 $\mu$ m paraffin tumor sections were float mounted on poly-L lysine coating slides, deparaffinized in xylene and rehydrated in a descending ethanol series. Anti-Ber-EP4 monoclonal antibody required enzymatic pre-treatment of the slides with $0.1 \%$ trypsin (Sigma, St. Louis, MO) for $10 \mathrm{~min}$ at $37^{\circ} \mathrm{C}$; for the other antibodies, slides were not enzimatically pretreated, but they were placed in $0.1 \mathrm{M}$ citrate buffer $(\mathrm{pH}$ 6.0) and boiled for $10 \mathrm{~min}$ in a microwave oven at $750 \mathrm{~W}$ to enhance antigenicity. Slides were washed in phosphate buffer and incubated for $10 \mathrm{~min}$ in $0.3 \%$ hydrogen peroxide to quench endogenous peroxidase activity. Slides were then loaded onto a LabVision automated immunostainer (NeoMarkers, Fremont, CA) and sequentially incubated with intervening washes in PBS for 5 min, with $10 \%$ ovalbumin for $15 \mathrm{~min}$ to reduce non-specific background staining, primary antibody for $60 \mathrm{~min}$ at room temperature, the appropriate biotinylated linking antibody (NeoMarkers, Fremont, CA) for $10 \mathrm{~min}$, peroxidase-labeled streptavidin (NeoMarkers, Fremont, CA) for $10 \mathrm{~min}$, and finally with 3,3'-diaminobenzidine chromogen substrate for $10 \mathrm{~min}$. Slides were then thoroughly rinsed in distilled water and counterstained with Mayer's haematoxylin, dehydrated, cleared in xylene and finally mounted in Entellan. Appropriate positive and negative controls were included for each marker. A panel of eight markers was used. Mouse anti-human antibodies included anti-CEA (dilution 1:100; NeoMarkers, Fremont, CA), polyclonal anti-calretinin (dilution 1:1000; NeoMarkers, Fremont, CA), monoclonal anti-CD15 (Leu-M1) (dilution 1:4; Bec-

Table 2: Growth progression of IST-Mes3 cell line after orthotopic implantation in nude mice.

\begin{tabular}{|c|c|c|c|c|c|c|c|c|c|}
\hline Days after implantation & $<56$ & 60 & 65 & 71 & 73 & 80 & 87 & 94 & 98 \\
\hline $\mathrm{N}^{\circ}$ of animals with tumor nodules ${ }^{1}$ & $0 / 5$ & $1 / 5$ & $2 / 5$ & $1 / 5$ & $1 / 5$ & $0 / 5$ & $1 / 5$ & $1 / 5$ & $2 / 5$ \\
\hline $\mathrm{N}^{\circ}$ of tumor nodules detected in each animal & - & $>20$ & $>20$ & $>20$ & $>20$ & - & $>20$ & $>20$ & $>20$ \\
\hline
\end{tabular}

$2 \times 10^{6}$ IST-Mes3 cells were injected into the pleural cavity of nude mice. Five animals were sacrificed when they became dyspneic or at indicated times and tumor nodules were counted, measured, removed and frozen for immunohistochemical analysis. Data shown report tumor development in individual animals. 
Table 3: Growth progression of IST-Mes3/2P cell line after orthotopic implantation in nude mice.

\begin{tabular}{|c|c|c|c|c|c|c|}
\hline Days after implantation & 54 & 61 & 68 & 75 & 82 & 89 \\
\hline Mediastinum nodules & $<10^{1}$ & $<10^{2}$ & $<10^{3}$ & $<10^{3}$ & $10-20^{3}$ & $10-20^{3}$ \\
\hline Pericardium nodules & $<101$ & $<10^{2}$ & $<10^{3}$ & $<10^{3}$ & $10-20^{3}$ & $10-20^{3}$ \\
\hline Parietal Pleura nodules & $<101$ & $<10^{2}$ & $<10^{3}$ & $<10^{3}$ & $10-20^{3}$ & $10-20^{3}$ \\
\hline Lungs nodules & & - & - & - & $<10^{2}$ & $<10^{2}$ \\
\hline Diaphragms nodules & - & - & - & - & $<10^{2}$ & $<10^{2}$ \\
\hline
\end{tabular}

$2 \times 10^{6}$ IST-Mes3/2P cells were injected into the pleural cavity of nude mice. At indicated times mice were sacrificed and tumor nodules were counted, measured, removed and frozen for immunohistochemical analysis. Data shown are mean of 5 mice.

I Nodule diameter $\leq \mathrm{I} \mathrm{mm;}{ }^{2}$ Nodule diameter $=2-3 \mathrm{~mm} ;{ }^{3}$ Nodule diameter $\geq 3$. No nodules were found before the days indicated in the table.

ton Dickinson, NJ), monoclonal anti-Ber-EP4 (dilution 1:100; NeoMarkers, Fremont, CA), monoclonal anticytokeratin 8 and 18 (dilution 1:50; Biomeda, Foster City, CA), monoclonal anti-EMA (dilution 1:500; NeoMarkers, Fremont, CA). monoclonal anti-mesothelioma (HBME-1) (dilution 1:25; NeoMarkers, Fremont, CA), monoclonal anti-podoplanin (dilution 1:50; Serotec, Dusseldorf, Germany).

\section{Hematoxylin-and-eosin staining}

Tumors were placed in OTC compound and snap frozen in liquid nitrogen and stored at $-80^{\circ} \mathrm{C}$. Frozen section $(10-20 \mu \mathrm{m})$ were fixed with cold acetone (5 min), acetone/chlorophorm $1 / 1$ (5 $\mathrm{min})$, cold acetone (5 $\mathrm{min})$. Slides were then rinsed with water for $10 \mathrm{~min}$, stained with Mayer's Hematoxylin Solution for $10 \mathrm{~min}$ (Sigma, St. Louis, MO), rinsed with water for $10 \mathrm{~min}$ and then stained with eosin $0.5 \%$ for $30 \mathrm{sec}$ (Sigma, St. Louis, MO). Slides were then dehydrated through $95 \%$ alcohol ( $5 \mathrm{~min}$.) and 2 changes of absolute alcohol, 5 min each, cleared in 2 changes of xylene $(5 \mathrm{~min})$ and finally mounted with xylene based mounting medium.

\section{Results}

\section{Growth of human MPM cells in nude mice}

Human MPM cell lines were tested for their ability to form tumors after intrapleural and subcutaneous injection in nude mice. Table I summarizes the tumor take rates of these cell lines. Tab. II, and III summarize the growth rate of these cell lines after orthotopic implantation, whereas
Fig. 1. shows their growth rate following subcutaneous implantation. IST-Mes 2 cells were unable to grow in nude mice. By contrast, $2 \times 10^{6}$ IST-Mes 3 or MMB- 1 tumor cells had a take-rate of $100 \%$ when injected into the left pleural cavity. The mean survival time was of $72.5 \pm 6.4$ days for mice injected with MM-B1 cells; $81.5 \pm 21.7$ days for mice injected with the IST-Mes 3 cells and $69.6 \pm 14.5$ days for mice injected with the IST-Mes3/2P cells. These mice were sacrificed when moribund, or at different times after cell injection as specified in Tab. I, II, III and IV. Animals injected with the IST-Mes3 cells were analyzed when they became dyspneic because of the tumor growth rate varies from animal to animal. These variations were not observed upon in vitro culture of IST-Mes3 tumor as shown by the analysis of the growth rate of IST-Mes3/2P cells. Tumor cells grew on both sides of parietal and visceral pleura, diaphragm and mediastinum; at later times, tumor invasion into lung parenchyma was observed (Fig. $2,3)$. No pneumothorax was evidenced in the mice. Pleural effusions as well as lymph node metastasis were noted only in the later stages of orthotopic growth of MM-B1, IST-Mes3 and IST-Mes3/2P cells. MM-B1 and IST-Mes2 cells did not grow when injected subcutaneously. ISTMes 3 cells started to grow only at forty days after tumor cell injection. This lag phase was independent on the number of cells injected (Fig. 1).

\section{Immunohistochemical analysis}

MPM cells were injected into pleura cavity of nude mice and tumor samples were collected for immunohisto-

Table 4: Growth progression of MM-B I cell line after orthotopic implantation in nude mice.

\begin{tabular}{|c|c|c|c|c|c|c|}
\hline Days after implantation & 38 & 45 & 52 & 59 & 66 & 73 \\
\hline Mediastinum nodules & $<10^{1}$ & $10-201$ & $10-20^{2}$ & $10-20^{2}$ & $>20^{3}$ & $>20^{3}$ \\
\hline Pericardium nodules & $<101$ & $10-201$ & $10-20^{2}$ & $10-20^{2}$ & $>20^{3}$ & $>20^{3}$ \\
\hline Parietal Pleura nodules & - & - & - & $10-20^{2}$ & $>20^{3}$ & $>20^{3}$ \\
\hline Lungs nodules & - & - & - & $10-20^{2}$ & $>20^{3}$ & $>20^{3}$ \\
\hline Diaphragms nodules & - & - & - & - & - & - \\
\hline
\end{tabular}

$2 \times 10^{6} \mathrm{MM}-\mathrm{BI}$ cells were injected into the pleural cavity of nude mice. At indicated times, mice were sacrificed and tumor nodules were counted, measured, removed and frozen for immunohistochemical analysis. Data shown are mean of 5 mice.

I Nodule diameter $\leq \mathrm{I} \mathrm{mm;}{ }^{2}$ Nodule diameter $2-3 \mathrm{~mm} ;{ }^{3}$ Nodule diameter $\geq 3 \mathrm{~mm}$. No nodules were found before the days indicated in the table. 


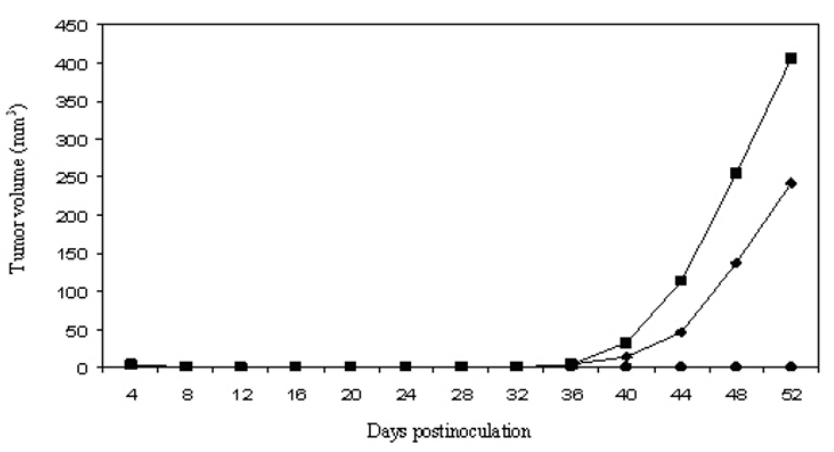

Figure I

Subcutaneous growth of MPM cells. Subcutaneously growth of MPM cells in nude mice. $\bullet=$ IST-Mes3 $\left(2 \times 10^{6}\right.$ cells injected), $\boldsymbol{\square}=$ IST-Mes3 $\left(4 \times 10^{6}\right.$ cells injected $), \boldsymbol{\Delta}=$ IST-Mes $2\left(2 \times 10^{6}\right.$ cells injected $), 0=$ MM-BI $\left(2 \times 10^{6}\right.$ cells injected). Tumor volume was calculated using the formula: $V$ $\left(\mathrm{mm}^{3}\right)=\left(\mathrm{D} \times \mathrm{d}^{2}\right) / 2$, where $\mathrm{d}(\mathrm{mm})$ and $\mathrm{D}(\mathrm{mm})$ are the smallest and largest perpendicular tumor diameters, respectively.

chemical analysis. CD31 staining revealed that tumor mass was highly vascularized (Fig. 3). For the phenotypic characterization of tumor mass, a panel of eight markers was used (Tab. 5). Recent findings showed that Mesothelin and TTF-1 have a limited value in assisting in the diagnosis of Mesothelioma and therefore were not used $[13,14]$. CEA and BerEP4 are adenocarcinoma specific markers and therefore are nor expressed by mesothelioma. Calretinin and HBME-1 are positive markers shared

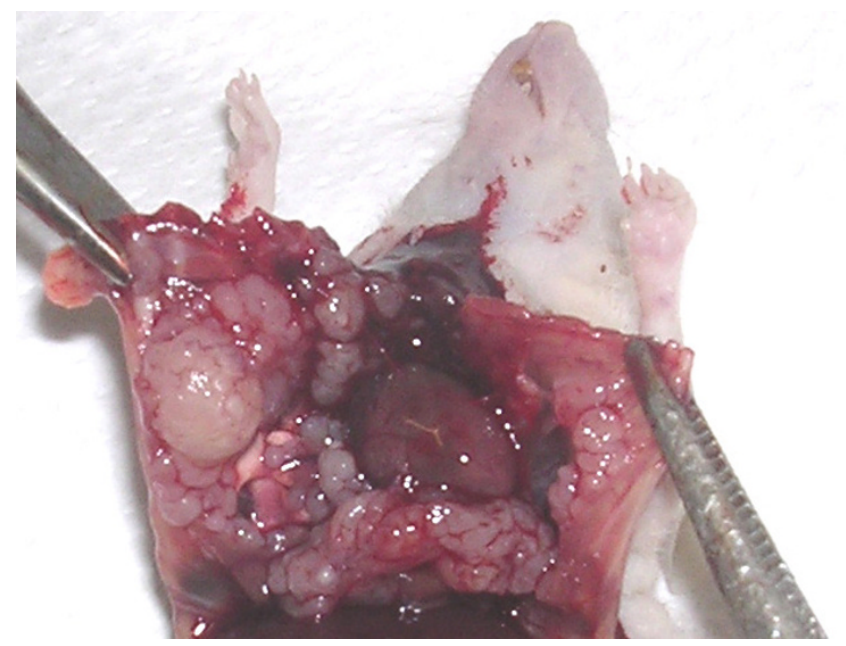

Figure 2

Pleural MPM nodules. IST-Mes 3 cells $\left(2 \times 10^{6}\right.$ in $100 \mu \mathrm{l}$ of HBSS) were injected into the left pleural cavity of nude mice. Tumor masses completely invaded the thoracic and visceral pleural and the lungs. The irregular growth of this cell line is evidenced by a major bulk of tumor in the right chest. by both epithelioid and biphasic variants of mesothelioma, whereas CD15 is a negative marker. Surface expression of the epithelial membrane antigen (EMA) is a marker that discriminates between reactive proliferation of mesothelial cells and malignant mesothelioma. The epithelia of biphasic mesotheliomas show strong reactivity for Cytokeratin 8/18, whereas Podoplanin is the most recently recognized marker for epithelioid mesotheliomas.

\section{Discussion}

New strategies for MPM treatment, which include inhibition, of angiogenesis, induction of tumor cell apoptosis, gene therapy and vaccines [15], need clinically representative animal models to test new drugs and explore tumor biology.

In this work we established a non invasive orthotopic model of human MPM by injecting the cancer cells directly into the pleural cavity of nude mice. The characteristics of tumor growth resemble those observed in tumor-bearing patients, with colonization of parietal and visceral pleura, diaphragm, mediastinum and, at later stages, lung parenchyma. We analyzed the tumorigenicity of three different human MPM cell lines, which exhibited different biological behaviors in vivo. Interestingly, the growth of MM-B1 cells seems to be site-specific as they did not form tumor masses when injected subcutaneously. Differently, the IST-Mes3 cells grow subcutaneously with a latency which does not depend on the number of cells injected (Fig. 1). This resembles some human situations in which cancer cells start to grow exponentially and form manifest tumor masses only after a long period of time from the acquisition of the tumorigenic phenotype.

As previously reported, neo-angiogenesis is an important process in MPM and protocols to inhibit this process are currently under investigation. Our model can be useful to study angiogenesis in MPM as tumors displayed high density of micro-vessels. IST-Mes 3 tumor grew with a latency of 60 days and this period remained substantially constant after tumor passage in mice. All the cell lines tested were unable to form metastases in the visceral organs, likely due to lack of time for tumor dissemination as the rapid spreading of the tumor cells into the pleural cavity dramatically resulted in mouse death. Among the cell lines tested, the MM-B1 cells seem to be the more appropriate for drug evaluation. In fact, as shown in Tab. II, the IST-Mes3 cells grow very rapidly to follow the progression of the disease, colonizing the entire pleural cavity and dramatically affecting the physical conditions of the mice which become cachectic and dyspneic, and the latency of tumor takes varies from animal to animal. The results obtained with the IST-Mes3/2P cell show that these varia- 

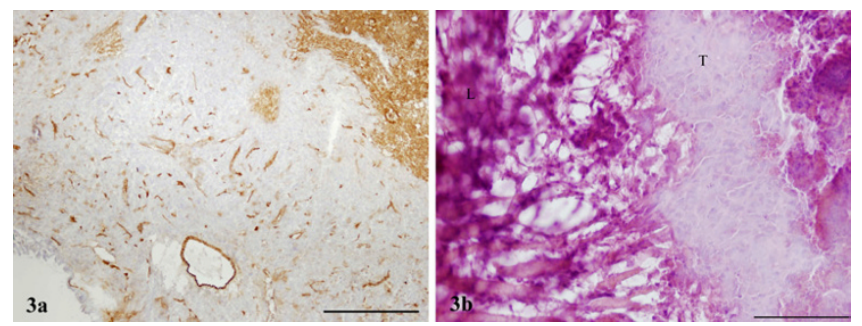

Figure 3

Orthotopic MPM histology. Fig. 3a. Frozen sections of tumors grown into the pleural cavity of nude mice injected with IST-Mes3 cells were stained with an anti-mouse CD3 I antibody. Tumors were intensively stained revealing an intricate network of microvessels. Bar $=500 \mu \mathrm{m}$. Fig. 3b. H\&E staining of tumor invading the lung. T: tumor, L: lung. Bar $=$ $100 \mu \mathrm{m}$.

tions are not observed when ex vivo tumor cells are cultured in vitro.

The growth rate of MM-B1 cells is reproducible. Tumors develop in all animals with a similar latency and the rate of tumor growth is slow enough to follow the progression of the disease. In this context, a noninvasive imaging methodology would be a useful tool to follow tumor development.

IST-Mes 2 cells did not grow in nude mice, but, since the epithelioid phenotype is the most common sub-type of mesothelioma, we plan to set up an orthotopic model using different ephitelioid cells.

Immunohistochemistry of tumors growing in the nude mice showed that MM-B1 and IST-Mes3 cells maintained the mesothelioma-specific characteristics, thus confirming the validity of the orthotopic model here established.

Table 5: Phenotypic characterizzation of MM-BI and IST-Mes3 cells after orthotopic implantation in nude mice.

\begin{tabular}{lll} 
& Cell lines & \\
\hline Marker & IST-Mes3 & MM-B I \\
\hline CEA & - & - \\
Calretinin & + & + \\
CDI5 (LeuMI) & - & - \\
Ber-EP4 & - & - \\
Cytokeratin 8/I8 & + & + \\
EMA & + (membrane) & + (membrane) \\
HBME-I & + & + \\
Podoplanin & + & + \\
\hline
\end{tabular}

IST-Mes3 and MM-BI cells were injected into the pleural cavity of nude mice. At indicated times the mice were sacrificed and tumor nodules were removed and frozen for immunohistochemical analysis of mesothelioma-specific markers.

\section{Conclusion}

Overall, this work describes the biological behavior of human MPM cells injected in the pleural cavity of nude mice. Because of the similarity of this orthotopic model with the human disease, the simplicity of execution and the reproducibility of the results, we propose this model as an useful tool for in vivo MPM studies.

\section{Competing interests}

The author(s) declare that they have no competing interests.

\section{Authors' contributions}

DM performed the orthotopic and subcutaneous implantation of cancer cells in nude mice, the autopsy and the immunoassays. AC carried out the cells culture and participated in the immunohistochemical analysis. GS designed and coordinated the study. PA participated in the coordination of the study and helped to draft the manuscript. SO and RL performed the phenotypic characterization on MPM cells orthotopically implanted in nude mice. All the authors read and approved the final manuscript.

\section{Acknowledgements}

We thanks Roberta Lucciarini, Consuelo Amantini and Maria Rita Rippo for technical advices and help. This work was supported and approved by the Italian Ministry of Health and the University of Camerino (Italy).

\section{References}

I. Antman $\mathrm{KH}$ : Natural history and epidemiology of malignant mesothelioma. Chest 1993, 103:73S-76S

2. Edwards JG, Swinson DE, Jones JL, Muller S, Waller DA, O'Byrne KJ: Tumor necrosis correlates with angiogenesis and is a predictor of poor prognosis in malignant mesothelioma. Chest 2003. 124:1916-1923.

3. Stewart JH, Nguyen DM, Chen GA, Schrump DS: Induction of apoptosis in malignant pleural mesothelioma cells by activation of the Fas (Apo-I/CD95) death-signal pathway. J Thorac Cardiovasc Surg 2002, I 23:295-302.

4. Rippo MR, Moretti S, Vescovi S, Tomasetti M, Orecchia S, Amici G, Catalano A, Procopio A: FLIP overexpression inhibits death receptor-induced apoptosis in malignant mesothelial cells. Oncogene 2004, 23:7753-7760.

5. Edwards JG, Cox G, Andi A, Jones JL, Walker RA, Waller DA, $O$ 'Byrne KJ: Angiogenesis is an independent prognostic factor in malignant mesothelioma. $\mathrm{Br} J$ Cancer 200I, 85:863-868.

6. Catalano A, Romano M, Robuffo I, Strizzi L, Procopio A: Methionine aminopeptidase-2 regulates human mesothelioma cell survival: role of $\mathrm{Bcl}-2$ expression and telomerase activity. $\mathrm{Am} J$ Pathol 200I, I59:72I-73I.

7. Sterman DH, Albelda SM: Advances in the diagnosis, evaluation, and management of malignant pleural mesothelioma. Respirology 2005, 10:266-283.

8. Le Pimpec-Barthes F, Bernard I, Abd Alsamad I, Renier A, Kheuang L, Fleury-Feith J, Devauchelle P, Quintin Colonna F, Riquet M, Jaurand MC: Pleuro-pulmonary tumours detected by clinical and chest $X$-ray analyses in rats transplanted with mesothelioma cells. Br J Cancer 1999, 81: I344- I350.

9. Colt HG, Astoul P, Wang X, Yi ES, Boutin C, Hoffman RM: Clinical course of human epithelial-type malignant pleural mesothelioma replicated in an orthotopic-transplant nude mouse model. Anticancer Res 1996, 16:633-639.

10. Nakataki E, Yano S, Matsumori Y, Goto H, Kakiuchi S, Muguruma H, Bando Y, Uehara H, Hamada H, Kito K, Yokoyama A, Sone S: Novel orthotopic implantation model of human malignant pleural mesothelioma (EHMES-10 cells) highly expressing vascular 
endothelial growth factor and its receptor. Cancer Sci 2006, 97:183-19|.

11. Orengo AM, Spoletini L, Procopio A, Favoni RE, De Cupis A, Ardizzoni A, Castagneto B, Ribotta M, Betta PG, Ferrini S, Mutti L: Establishment of four new mesothelioma cell lines: characterization by ultrastructural and immunophenotypic analysis. Eur Respir J 1999, 13:527-534.

12. Pass HI, Stevens EJ, Oie H, Tsokos MG, Abati AD, Fetsch PA, Mew DJ, Pogrebniak HW, Matthews WJ: Characteristics of nine newly derived mesothelioma cell lines. Ann Thorac Surg 1995, 59(4):835-844.

13. King JE, Thatcher N, Pickering CA, Hasleton PS: Sensitivity and specificity of immunohistochemical markers used in the diagnosis of epithelioid mesothelioma: a detailed systematic analysis using published data. Histopathology 2006, 48:223-232.

14. Ordonez NG: Application of mesothelin immunostaining in tumor diagnosis. Am J Surg Pathol 2003, 27:1418-1428.

15. Nowak AK, Lake RA, Kindler HL, Robinson BWS: New approaches for mesothelioma: biologics, vaccines, gene therapy and other novel agents. Semin Oncol 2002, 29:82-96.

\section{Pre-publication history}

The pre-publication history for this paper can be accessed here:

http://www.biomedcentral.com/1471-2407/6/130/pre

pub

Publish with Biomed Central and every scientist can read your work free of charge

"BioMed Central will be the most significant development for disseminating the results of biomedical research in our lifetime. "

Sir Paul Nurse, Cancer Research UK

Your research papers will be:

- available free of charge to the entire biomedical community

- peer reviewed and published immediately upon acceptance

- cited in PubMed and archived on PubMed Central

- yours - you keep the copyright

Submit your manuscript here:

http://www.biomedcentral.com/info/publishing_adv.asp 